\title{
(2) OPEN ACCESS \\ Supportive and Palliative Care Indicators Tool prognostic value in older hospitalised patients: a prospective multicentre study
}

\section{Ruth Piers (1) ${ }^{1,2}$ Isabelle De Brauwer, ${ }^{3,4}$ Hilde Baeyens, ${ }^{5}$ Anja Velghe, ${ }^{1,2}$ Lineke Hens, ${ }^{6}$ Ellen Deschepper, ${ }^{7}$ Séverine Henrard ${ }^{4,8}$ Michel De Pauw ${ }^{2,6}$ Nele Van Den Noortgate, ${ }^{1,2}$ Marie De Saint-Hubert ${ }^{9}$}

For numbered affiliations see end of article.

\section{Correspondence to}

Prof Ruth Piers, Department of Geriatric Medicine, University Hospital Ghent, Gent, Oost-

Vlaanderen, Belgium; ruth.piers@uzgent.be

Received 15 March 2021 Accepted 9 May 2021

\section{Check for updates}

(C) Author(s) (or their employer(s)) 2021. Re-use permitted under CC BY-NC. No commercial re-use. See rights and permissions. Published by BMJ.

\footnotetext{
To cite: Piers $R$, De Brauwer I, Baeyens $\mathrm{H}$, et al. BMJ Supportive \& Palliative Care Epub ahead of print: [please include Day Month Year]. doi:10.1136/ bmjspcare-2021-003042
}

\section{ABSTRACT}

Background An increasing number of older patients are hospitalised. Prognostic uncertainty causes hospital doctors to be reluctant to make the switch from cure to care. The Supportive and Palliative Care Indicators Tool (SPICT) has not been validated for prognostication in an older hospitalised population.

Aim To validate SPICT as a prognostic tool for risk of dying within one year in older hospitalised patients.

Design Prospective multicentre study. Premorbid SPICT and 1-year survival and survival time were assessed.

Setting/participants Patients 75 years and older admitted at acute geriatric $(n=209)$ and cardiology units (CUs) $(n=249)$ of four hospitals. Results In total, 59.3\% (124/209) was SPICT identified on acute geriatric vs $40.6 \%$ (101/249) on CUs $(p<0.001)$. SPICT-identified patients in CUs reported more functional needs and more symptoms compared to SPICT non-identified patients. On acute geriatric units, SPICT-identified patients reported more functional needs only. The HR of dying was 2.9 (95\% Cl 1.1 to 8.7$)$ in SPICT-identified versus non-identified after adjustment for hospital strata, age, gender and did not differ between units. One-year mortality was $24 \%$ and $22 \%$, respectively, on acute geriatric versus CUs ( $p=0.488)$. Pooled average sensitivity, specificity and partial area under the curve differed significantly between acute geriatric and CUs $(p<0.001)$, respectively, $0.82(95 \% \mathrm{Cl} 0.66$ to 0.91$), 0.49(95 \% \mathrm{Cl} 0.40$ to $0.58)$ and 0.82 in geriatric vs $0.69(95 \% \mathrm{Cl} 0.42$ to 0.87$), 0.66(95 \% \mathrm{Cl} 0.55$ to 0.77$)$ and 0.65 in CUs.

Conclusions SPICT may be used as a tool to identify older hospitalised patients at risk of dying within 1 year and who may benefit from a palliative care approach including advance care

\section{Key messages}

What was already known?

- Prognostication is essential for end-of-life decision making.

- Supportive and Palliative Care Indicators Tool (SPICT) has not been validated in older hospitalised persons.

What are the new findings?

- The hazard of dying was three times higher in older SPICT-identified patients.

- SPICT prognostic accuracy was good in acute geriatric units and moderate in cardiology units.

What is their significance?

a. Clinical

- SPICT may be used as a tool to identify older hospitalised patients at risk of 1year mortality in whom a palliative care approach is warranted.

b. Research

- SPICT has similar prognostic accuracy in older hospitalised persons compared with the widely used Clinical Frailty Scale, but head-to-head comparisons are missing.

- The question remains what kind of care model is best to start after identification: introducing expert geriatric care or expert palliative care, or a new care model in which both geriatric and palliative expertise are integrated?

planning. The prognostic accuracy of SPICT is better in older patients admitted at the acute geriatric versus the $\mathrm{CU}$.

\section{INTRODUCTION}

In the past decades, we are experiencing a rapid ageing in Western countries. People 
live longer but with more chronic diseases and care dependence at the end of life. As a result, an increasing number of older patients are hospitalised. ${ }^{1}$ In 2014, $25 \%$ of all hospitalised patients in Belgium were 75 years old and over. As in all Western countries, it is expected to rise. Some of these patients are admitted on acute geriatric units (AGUs), known for its focus on comprehensive geriatric assessment, early rehabilitation, early discharge planning and person-centred care; others are admitted on non-geriatric wards in which there is a more single-disease approach. ${ }^{2}$ In Belgium, each acute care hospital has a geriatric care programme where frail older patients are mainly admitted to acute beds managed by the geriatricians. When older people are admitted on non-geriatric wards, the geriatric liaison team offers comprehensive geriatric assessment to older patients screened as frail or on request of the treating team. Each acute care hospital also has a palliative care liaison team where experts in palliative care can be consulted on request of the treating team.

As most people will use hospital services in their final year of life, hospitalisation may be important to initiate advance care planning. ${ }^{34}$ Early integration of a palliative care approach including advance care planning has proven to be beneficial for patients and families at the end of life: there is better quality of life in patients and less mental stress in family members ${ }^{5-8}$ without shortening of life. ${ }^{79}$ In particular, older hospitalised persons are at increased risk of being deprived from palliative care. ${ }^{10}{ }^{11}$ One of the main causes is prognostic uncertainty in the older patient, causing physicians to be less confident in making the switch from cure to care. ${ }^{12} 13$

The Supportive and Palliative Care Indicators Tool (SPICT) was developed for a more timely identification of patients with palliative care needs for firstline medicine. ${ }^{14}$ Besides self-reported palliative care needs, prognostication is essential in medical decision making. ${ }^{15} 16$ Prognostication is essential for many reasons such as supporting patient-centred communication and advance care planning and avoiding the burden of intense level of care in patients with poor prognosis. ${ }^{15} 16$ Until now, SPICT has insufficiently been validated in older persons neither in the acute care hospital nor for prognostication. To the best of the authors' knowledge, there is only one study that used SPICT for prognostication in AGU which gave promising results but was limited by its retrospective design. ${ }^{17}$

The aim of this study was to assess prospectively the prognostic value of SPICT for risk of death within 1 year in older persons admitted to the hospital. As the consequences of a false-negative result (deny patients a palliative care approach including advance care planning) outweigh the consequences of a false-positive result (possibly starting palliative care principles too early), ${ }^{12} 18$ the authors value sensitivity as being more important than specificity in the assessment of the prognostic accuracy. In each of the research questions, comparison is made between older people admitted at the AGU versus a disease-specific ward as we know that the people admitted on the AGU are more frail than people admitted in disease-specific wards. ${ }^{2}$

\section{METHODS}

\section{Design, participants and settings}

Patients aged 75 years and older were prospectively recruited from the AGU and cardiology unit (CU) of four hospitals in Belgium. The CU was chosen as an example for a non-geriatric ward because cardiovascular disease is one of the most prevalent comorbidities in older patients. CUs manage younger and older patients presenting with acute cardiovascular disease without need for intensive care. All older patients with a length of stay of more than 48 hours were eligible for the study (in order to be able to do a thorough assessment). We excluded patients who were transferred from other wards (premorbid SPICT is more difficult to assess when patients had already been admitted elsewhere), and patients who were already included earlier in the study.

\section{Data collection and measures}

From January to July 2018, junior doctors trained in geriatric medicine and experienced members of the geriatric team assessed the premorbid palliative care needs by means of the first part of SPICT, asking the patient/family to think about the situation 2 weeks before admittance, blinded from the treating physician. SPICT combines 6 general and 23 disease-specific indicators regarding deteriorating health. ${ }^{14}$ Different versions of SPICT have been published, and the French and Dutch 2017 version is used in this study ( www.spict.org.uk); permission was obtained. There is SPICT identification when at least one general and one disease-specific indicator is present.

Sociodemographic information, basic and instrumental activities of daily living (iADLs) assessed by using Katz Scale ${ }^{19}$ and Lawton Scale, ${ }^{20}$ respectively, length of stay and comorbidity measured by Charlson Comorbidity Index ${ }^{21}$ were collected from the medical record after patient discharge (these data are obtained in routine care).

One year after admission, the patient and family were contacted by a junior doctor or data nurse to collect survival status and timing of death as main outcome measures.

\section{Statistical analysis}

Descriptive statistics were computed using IBM SPSS Statistics software V.25. For continuous data, range, median and IQR were computed and the MannWhitney U test was used for comparisons; categorical data were compared using Pearson's $\chi^{2}$ tests. The exact $\mathrm{p}$ values are reported, with statistical significance defined as $p \leq 0.05$. A multivariable Cox's 


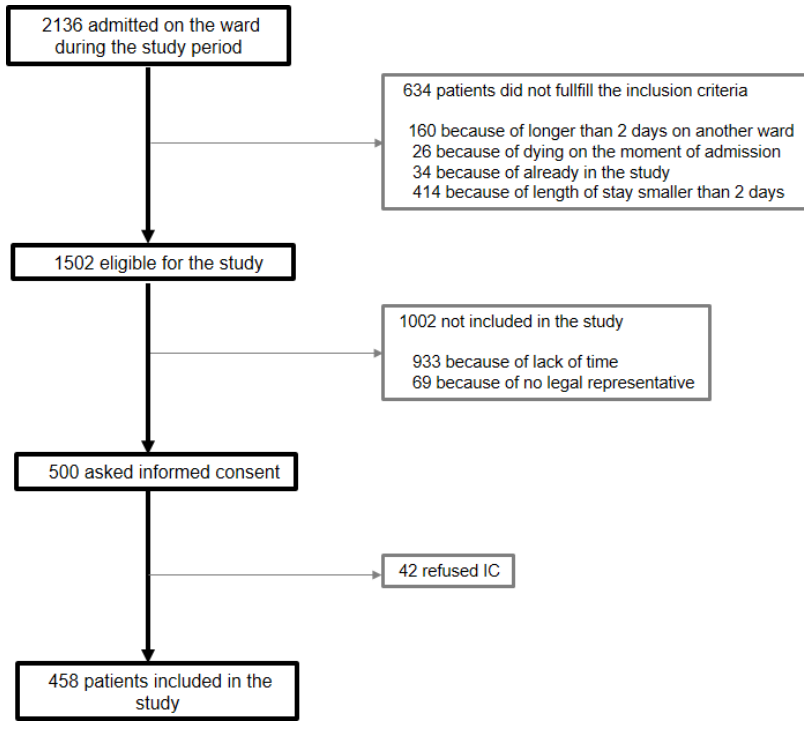

Figure 1 Flowchart of recruitment.IC: informed consent.

regression was used to assess the association between SPICT and 1-year mortality adjusted for age, gender and type of unit (fixed affects) and using hospital as random effect.

To assess diagnostic accuracy, summary receiver operating characteristic (SROC) curves were constructed to obtain the pooled values of sensitivity and specificity. Bivariate modelling for sensitivity and specificity together was performed in R V.3.5.2, using the mada package V.0.5. $8^{22}$ (https://cran.r-project.org/ web/packages/mada/vignettes/mada.pdf). Differences in mean sensitivity and specificity were assessed by means of a metaregression. As partial area under the curve (AUC) is restricted to clinically sensible thresholds, we put this measure forward as the measure of our preference. ${ }^{23}$

\section{RESULTS}

\section{Participants}

Of the 2136 older patients admitted during the study period, 634 were excluded mostly because of length of stay of less than 48 hours (most on CU) or staying more than 48 hours on another ward before coming to AGU or CU. Of 1502 patients eligible for the study, 933 were not included in a period in which the junior physician who asked for informed consent was on holiday or had too much clinical work. Furthermore, 44 patients refused to participate in the study (no informed consent) and 69 incompetent patients did not have a legal representative, leaving 458 patients for the study (figure 1).

\begin{tabular}{|c|c|c|c|}
\hline & $\begin{array}{l}\text { Acute geriatric unit }(\mathrm{n}=209) \\
\mathrm{n}(\%) \text { or median }(\mathrm{P} 25-\mathrm{P} 75)(\min -\max )\end{array}$ & $\begin{array}{l}\text { Cardiology unit }(\mathrm{n}=249) \\
\mathrm{n}(\%) \text { or median }(\mathrm{P} 25-\mathrm{P} 75)(\min -\max )\end{array}$ & $P$ value \\
\hline Hospital & & & 0.051 \\
\hline 1 & $60(28.7)$ & $46(18.5)$ & \\
\hline 2 & $62(29.7)$ & $80(32.1)$ & \\
\hline 3 & $27(12.9)$ & $46(18.5)$ & \\
\hline 4 & $60(28.7)$ & $77(30.9)$ & \\
\hline Age (years) & & & $<0.001^{*}$ \\
\hline $75-79$ & $19(9.1)$ & $78(31.3)$ & \\
\hline $80-84$ & $73(34.9)$ & $73(29.3)$ & \\
\hline $85-89$ & $69(33.0)$ & $66(26.5)$ & \\
\hline $90-94$ & $38(18.2)$ & $28(11.2)$ & \\
\hline $95-100$ & $10(4.8)$ & $4(1.6)$ & \\
\hline Gender-male & $85(40.7)$ & $141(56.6)$ & $0.001^{*}$ \\
\hline Residence before admittance & & & $0.001^{*}$ \\
\hline Home & $178(85.2)$ & $238(95.6)$ & \\
\hline Acute care hospital & $1(0.5)$ & $0(0.0)$ & \\
\hline Short-term stay in non-acute setting & $7(3.3)$ & $4(1.6)$ & \\
\hline Nursing home & $23(11.0)$ & $7(2.8)$ & \\
\hline $\begin{array}{l}\text { Charlson Age-Comorbidity Index (one } \\
\text { missing) }\end{array}$ & $7(5-9)(3-15)$ & $7(5-8)(3-15)$ & $0.024^{*}$ \\
\hline $\begin{array}{l}\text { ADL total score } 2 \text { weeks before } \\
\text { admittance (one missing) }\end{array}$ & $9(7-13)(1-24)$ & $7(6-9)(0-20)$ & $<0.001^{*}$ \\
\hline $\begin{array}{l}\text { iADL total score } 2 \text { weeks before } \\
\text { admittance (one missing) }\end{array}$ & $3(1-4)(0-7)$ & $5(3-6)(0-7)$ & $<0.001^{*}$ \\
\hline Total length of stay (one missing) & $15(10-21)(2-65)$ & $5(3-9)(0-34)$ & $<0.001^{*}$ \\
\hline
\end{tabular}


Table 2 Comparison of premorbid care needst between SPICT-identified and SPICT non-identified patients

\begin{tabular}{|c|c|c|c|c|c|c|}
\hline \multirow{3}{*}{$\begin{array}{l}\text { SPICT part general } \\
\text { indicators }\end{array}$} & \multicolumn{3}{|c|}{ Acute geriatric unit $((n=209)$} & \multicolumn{3}{|c|}{ Cardiology unit $(n=249)$} \\
\hline & SPICT non-identified & SPICT-identified & & SPICT non-identified & SPICT-identified & \\
\hline & n $(\%)$ & n $(\%)$ & $P$ value & n $(\%)$ & $\mathrm{n}(\%)$ & P value \\
\hline $\begin{array}{l}\text { Unplannend hospital } \\
\text { admission(s) }\end{array}$ & $83 / 85(97.6)$ & $118 / 124(95.2)$ & 0.477 & 109/148 (73.6) & $87 / 101(86.1)$ & $0.019^{*}$ \\
\hline Poor performance status & $10 / 85(11.8)$ & $54 / 124(43.5)$ & $<0.001^{*}$ & $10 / 148(6.8)$ & $33 / 101(32.7)$ & $<0.001^{*}$ \\
\hline Care dependency & $35 / 85(41.2)$ & $91 / 124(73.4)$ & $<0.001^{*}$ & $16 / 148(10.8)$ & 45/101 (44.6) & $<0.001^{*}$ \\
\hline Weight loss or underweight & $20 / 85(23.5)$ & $40 / 124(32.3)$ & 0.213 & $20 / 148(13.5)$ & $26 / 101(25.7)$ & $<0.001^{*}$ \\
\hline $\begin{array}{l}\text { Symptoms despite optimal } \\
\text { treatment }\end{array}$ & $15 / 85(17.6)$ & $33 / 124(26.6)$ & 0.137 & $13 / 148(8.8)$ & $42 / 101(41.6)$ & $<0.001^{*}$ \\
\hline $\begin{array}{l}\text { Patient/family asking } \\
\text { palliative care }\end{array}$ & $2 / 85(2.4)$ & $10 / 124(8.1)$ & 0.128 & $1 / 148(0.7)$ & $2 / 101(2.0)$ & 0.568 \\
\hline
\end{tabular}

tCare needs assessed blinded from the treating team. Situation of 2 weeks before admission was asked to patients and/or their families by means of SPICT part general indicators (14).

SPICT, Supportive and Palliative Care Indicators Tool.

Older patients admitted at the AGU were older, female and more dependent, according to ADL and iADL scores (table 1).

\section{SPICT characteristics}

All general indicators of SPICT were more prevalent in AGU versus CU, except for 'persistent symptoms' which was present in one in five older patients both on AGU and CU $(p=0.823)$. Lowest prevalence was the indicator concerning patient or family request for palliative care $(5.7 \%$ of patients on AGU, $1.2 \%$ on CU, $\mathrm{p}=0.007)$. The median AGU patient had two general indicators present vs one in CU $(p<0.001)$.

For the disease-specific indicators, the median in AGU was 1 (mostly frailty/dementia) vs 0 in the CU (when present, severe heart disease was most prevalent) $(<0.001)$.

In total, 59.3\% (124/209) was SPICT identified on AGUs vs $40.6 \%(101 / 249)$ on CUs ( $<<0.001)$. SPICTidentified patients in $\mathrm{CU}$ reported more functional needs and more symptoms compared with SPICT nonidentified patients on CU. On AGU, SPICT-identified patients reported more functional needs only (table 2 ).

\section{1-Year outcome and survival time analysis}

Of 458 patients, $2.8 \%$ died in the hospital. One-year mortality was known in 202 out of 209 AGU and 242 out of 249 CU patients; 1 year-mortality was $24.3 \%(\mathrm{n}=49 / 202)$ vs $21.5 \% \quad(\mathrm{n}=52 / 242)$, respectively $(\mathrm{p}=0.488)$. One-year mortality differed between SPICT-identified and SPICT non-identified patients on both units $(\mathrm{p}<0.001)$. Positive predictive value (PPV) of SPICT was comparable on both units: $33.9 \%$ on AGUs and $33.7 \%$ on CUs $(\mathrm{p}=0.972)$. The negative predictive value (NPV) was $89.3 \%$ and $86.8 \%$, respectively $(\mathrm{p}=0.582)$.

A first Cox regression model showed no significant interaction between ward (AGU vs CU) and SPICT. In the second Cox regression model without the interaction included, the HR for SPICT was 2.864 (95\%
CI 1.808 to 4.538$)(\mathrm{p}<0.001)$ after adjusting for age, gender and type of unit (figure 2).

\section{Diagnostic test accuracy}

The SROC curves are shown in figure 3. The likelihood ratio tests (metaregression) showed that there was a significant difference for ward ( $p$ sensitivity: 0.001, $p$ specificity: <0.001), meaning that the diagnostic accuracy differed significantly between AGU and CU (better on AGU). The pooled average sensitivity, specificity, AUC and partial AUC are presented in table 3. Partial AUC was 0.822 on AGU vs 0.651 on $\mathrm{CU}(\mathrm{p}<0.001)$.

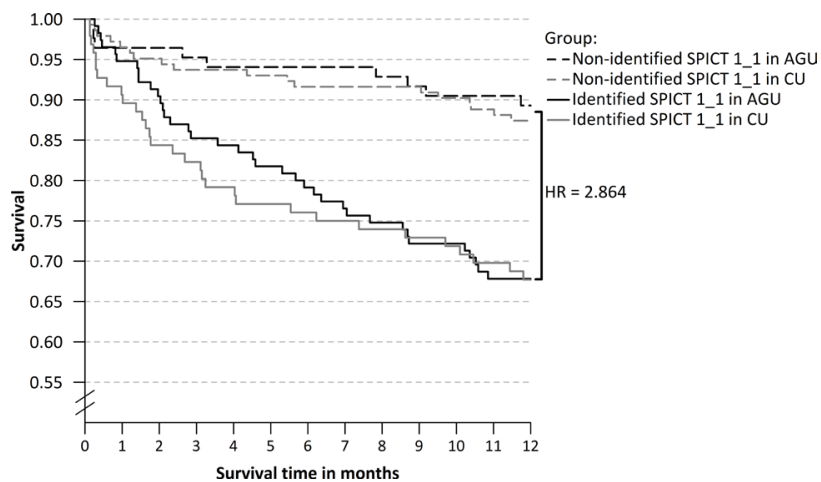

Figure 2 Time to death according to SPICT identification and type of unit

Legend: the presented HR is based on a Cox regression model after adjustment for age, gender and respecting strata of four hospitals. SPICT non-identified patients admitted at the geriatric unit (black dotted line); SPICT non-identified patients admitted at the CU (grey dotted line); SPICT-identified patients admitted at the geriatric unit (full black line), SPICT-identified patients admitted at the CU (full grey line). AGU, acute geriatric unit; CU, cardiology unit; SPICT, supportive and palliative care indicators tool. 


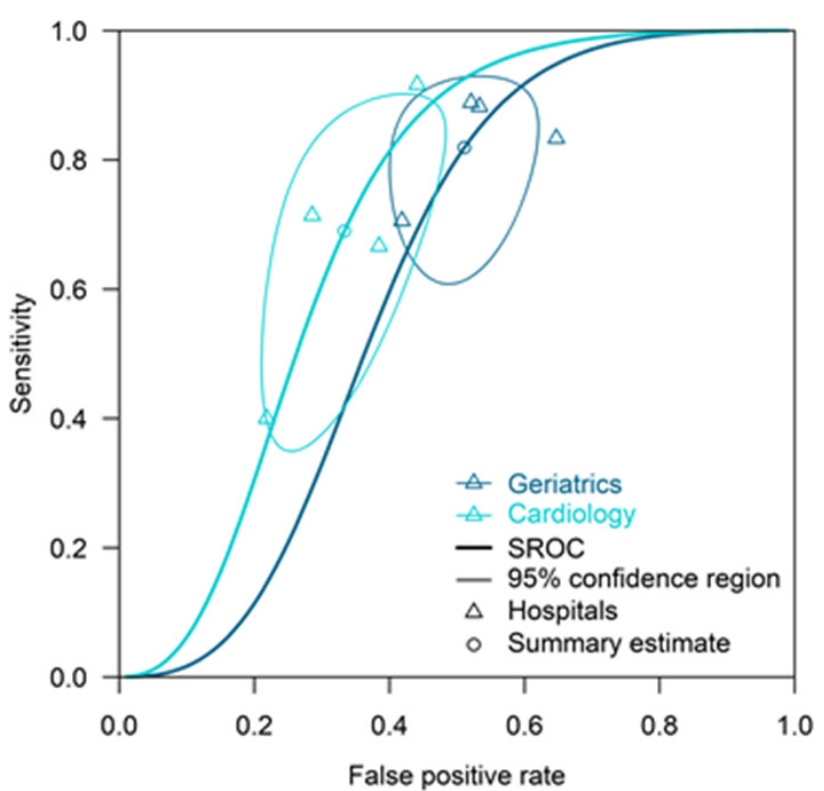

Figure 3 Summary ROC curves

Legend: the pooled estimate and SROC curve based on bivariate analysis $(n=458)$ are visualised in a scatter plot of the false-positive rate (1 - specificity) and the sensitivity for the individual hospitals, including $95 \%$ confidence regions for the pooled estimates. The results of the sampled wards are visualised by a triangle; the pooled estimate per type of ward (cardiology in light blue, acute geriatric unit in darker blue) is indicated by a circle. SROC, summary receiver operating characteristic.

\section{DISCUSSION \\ Main findings}

In a cohort of 458 older hospitalised patients, $60 \%$ of older patients admitted at AGUs and $40 \%$ of older people on CUs were SPICT identified. SPICTidentified patients in $\mathrm{CU}$ reported more functional needs and more symptoms compared with SPICT nonidentified patients on CU. On AGU, SPICT-identified patients reported more functional needs only.

In SPICT-identified patients, the hazard of mortality was three times higher compared with SPICT nonidentified patients. After 1 year, one in three had died vs $12 \%$ in those who were non-identified by SPICT. SPICT performed better as a prognostic tool in AGUs compared with CUs; the pooled sensitivity was 0.82 on AGU compared with 0.69 on cardiology. Specificity was 0.49 vs 0.67 , respectively, and partial AUC was 0.82 vs 0.65 .

\section{Discussion of results}

SPICT had good sensitivity and moderate specificity for predicting 1-year mortality in the older hospitalised patient. This accuracy is similar or better compared with other palliative care tools studied in a general adult hospitalised population as the GSF-PIG (Gold Standards Framework Proactive Identification Guidance) (sensitivity 0.78 , specificity 0.72 , PPV 38\%, NPV 94\%), ${ }^{18}$ NECPAL (Necesidades Paliativas) (sensitivity 0.91 , specificity 0.33 , PPV 33\%, NPV 91\% $)^{24}$ and PALLIAR (AUC 0.73). ${ }^{25}$

In contrast to the latter studies, our study focused on the older hospitalised person. To the best of our knowledge, we found only two other prospective studies exploring the prognostic accuracy for 1-year mortality specifically in such a population. Ritt et al compared five frailty instruments in two AGUs; the Clinical Frailty Scale ${ }^{26}$ showed best diagnostic accuracy with an AUC of $0.85 .{ }^{27}$ They hypothesised that the superiority of the Clinical Frailty Scale ${ }^{26}$ is due to the physician's judgement of the remaining life expectancy, which is absent in other frailty instruments ${ }^{27}$; the added value of clinical appraisal in prognostication is also a point of discussion in palliative care literature. ${ }^{28} 29$ Pilotto et al found that the Multidimensional Prognostic Index had an AUC of 0.76 for 1-year mortality ${ }^{30}$ comparable to our findings; however, the Multidimensional Prognostic Index is more extended in comparison to SPICT in which a short patient/family interview is needed, as well as a short medical history review.

This study showed that SPICT was less accurate in older patients hospitalised in the CU. Although the 1 -year mortality was the same for both units (one in five), the older persons on cardiology were less frail and had less severe comorbidities. A possible explanation for the difference in accuracy might be that older persons on cardiology die less because of frailty but more because of cardiac death, ${ }^{13}$ which might be insufficiently captured by SPICT. Indeed, the goldstandard tool for prognostication in heart failure, the Seattle Heart Failure Score, includes age, gender, heart function and creatinine. ${ }^{13} 31$ Fu and colleagues showed in a cohort of older hospitalised heart failure patients, that the Seattle Heart Failure Score had an AUC of 0.80 which exceeds the AUC of SPICT in this study. ${ }^{32}$ However, the advantage of SPICT lies in its applicability for a heterogeneous population, which makes hospital-based screening possible.

Table 3 Diagnostic accuracies of SPICT (bivariate analysis)

\begin{tabular}{lll}
\hline & Geriatric ward $(\mathrm{n}=209)$ & Cardiology ward $(\mathrm{n}=249)$ \\
\hline Pooled average measure & & \\
Sensitivity $(95 \% \mathrm{Cl})$ & $0.819(0.658$ to 0.914$)$ & $0.690(0.416$ to 0.874$)$ \\
Specificity $(95 \% \mathrm{Cl})$ & $0.489(0.401$ to 0.548$)$ & $0.667(0.548$ to 0.768$)$ \\
Partial AUC & 0.822 & 0.651 \\
\hline
\end{tabular}

AUC, area under the curve; SPICT, Supportive and Palliative Care Indicators Tool. 


\section{Limitations and strengths}

To the best of the authors' knowledge, this is the first study in hospitalised older patients comparing the prognostic accuracy of a palliative care tool between older patients treated on AGUs and on a diseasespecific ward. Another strength is the prospective multicentre design with few missing data.

However, there are some limitations. First, selection bias cannot be excluded: (1) two-thirds of eligible patients were not included because of time constraints, and we had no patient characteristics of the missing patients, so this was more a convenience sample than a cohort; this was due to working with junior doctors who often had too much clinical work to include patients in the study; finding resources for qualified study personnel is warranted in the future; (2) we excluded patients who were transferred from other wards and patients with short stays, probably excluding the most sick and the fittest older patients. This may give rise to bias, probably underestimation of the discriminative power. Furthermore, we are not sure if our results are generalisable to other disease-specific wards treating the older patient. This study must be viewed a meta-analysis of four samples for AGU and CU. For AGU, the 1 -year mortality rate of $24 \%$ is in line with other studies performed in different countries, ${ }^{27}$ underscribing the generalisability for AGUs.

\section{Practice implications}

The prognostic accuracy of SPICT for risk of dying within 1 year is similar compared with the widely used Clinical Frailty Scale ${ }^{26}$ tool and the Multidimensional Prognostic Index. ${ }^{30}$ These tools might help hospital clinicians to overcome prognostic paralysis and to earlier integrate a palliative care approach including advance care planning conversations. SPICT is a tool meant to identify patients who are at risk of deteriorating and dying. SPICT identification should prompt clinicians to initiate proactive holistic needs assessment, shared decision making about goals of care and anticipatory care planning. ${ }^{14}$ While basic palliative care should be considered as necessary to offer to SPICTidentified patients, patients with persistent symptoms should be offered specialised palliative care assessment and support when appropriate. Interestingly, patient or family request for palliative care was the lowestscoring general indicator ( $5 \%$ on AGUs, $1 \%$ on CUs). This low percentage is comparable to other studies, ${ }^{18}$ showing that there is a need not only for a mind shift from cure to care in clinicians ${ }^{33}$ but also for better acceptance of early palliative care in society. ${ }^{34} 35$ The advantage of SPICT over geriatric assessment tools such as the Clinical Frailty Scale ${ }^{26}$ is its focus on care needs as pronounced by the patient and the family, which may give way to introducing a palliative care approach more easy.

However, there is a need for research about how to introduce SPICT as a hospital-based screening tool. ${ }^{36} 37$ More importantly, we lack evidence on what kind of care model is best to start after identification in acute care hospitals, and more particular in older hospitalised patients. The needs of SPICT-identified older patients on the $\mathrm{CU}$ are mainly in the functional domain: one may thus wonder if SPICT should be used to introduce expert geriatric care or expert palliative care or a new care model in which both geriatric and palliative expertise are integrated. It is also under debate if geriatricians and disease-specific specialists should be the ones providing a palliative care approach or if specialised palliative care should come into the wards ${ }^{38}$ though there is a preference for combining both. ${ }^{13}{ }^{39}$ However, there is a lot of diversity in the studied models of integrated palliative care and thus a call for the development of standardised and conceptually unambiguous strategies. ${ }^{9} 4041$

Furthermore, we put forward that we preferred a high sensitivity above specificity in order not to deprive older people from a palliative care approach. However, when considering practical feasibility and costs on a population level, one may choose specificity over sensitivity. Also for treatment limitation decisions, physicians might prefer a higher PPV. When two out of three of SPICT-identified patients are still alive after 1 year, treating physicians do no harm by starting advance care planning and focus on symptom management. However, they must stay precautious not to undertreat older patients and optimally invest in physical revalidation to regain functionality. In short, SPICT can be seen as a good way of starting to think and talk about the right balance between revalidation/ life prolongation and comfort in the older patient, always in the perspective of what the patient truly values in life.

\section{FUTURE RESEARCH}

Further studies should assess the accuracy of SPICT in other contexts (emergency department, nursing homes, etc) by different professionals. It would be interesting to make a head-to-head comparison with the Clinical Frailty Scale and to study if clinical appraisal adds to prognostic accuracy.

Future studies should investigate the feasibility, cost and impact of screening for risk of 1-year mortality and palliative care needs in hospitals.

\footnotetext{
Author affiliations

${ }^{1}$ Department of Geriatric Medicine, University Hospital Ghent, Ghent, Belgium ${ }^{2}$ Department of Internal Medicine and Pediatrics, Ghent University Faculty of Medicine and Health Sciences, Ghent, Belgium

${ }^{3}$ Department of Geriatric Medicine, Cliniques universitaires Saint-Luc, Bruxelles, Belgium

${ }^{4} U C L$ Institute of Health and Society, Bruxelles, Belgium

${ }^{5}$ Department of Geriatric Medicine, AZ Alma campus Eeklo, Eeklo, Belgium

${ }^{6}$ Department of Cardiology, University Hospital Ghent, Ghent, Belgium

7 Biostatistics Unit, Department of Public Health and Primary Care, Ghent

University, Ghent, Belgium

${ }^{8}$ UCLouvain Louvain Drug Research Institute, Bruxelles, Belgium

${ }^{9}$ Department of Geriatric Medicine, CHU UCL Namur, Yvoir, Namur, Belgium
} 
Acknowledgements The authors thank Maes H, De Bock R, Van de Vyver C, Duyver E, Cornil C, de la Kethulle de Ryhove $\mathrm{C}$ and Badin $\mathrm{H}$ for the data collection and data entry, and Guédès A for making recruitment possible.

Contributors The authors confirm that they have participated sufficiently in the work to take public responsibility for appropriate portions of the content and the manuscript has been read and approved by all the named authors and that there are no other persons who satisfied the criteria for authorship but are not listed. The order of authors listed in the manuscript has been approved by all the authors. RP and NVDN conceived and designed the study; RP, IDB, AV, HB, LH MDP and MDS-H were involved in recruitment and data collection; RP, ED and SH performed the data analysis; RP drafted the manuscript; IDB, AV, HB, AV, LH, ED, SH, MDP, NVDN and MDS-H helped in critical revision for important intellectual content; all authors were involved in final approval of the version to be published.

Funding This work was supported by Fund Marie-Thérèse De Lava, King Baudouin Foundation, Belgium (to RP).

Competing interests None declared.

Patient consent for publication Not required.

Ethics approval The study was approved by all ethics committees (Belgian Registration number B670201734355, 18 January 2018, Ghent University Hospital, Belgium); all patients or their legal representative in case of incompetence were asked for oral and written informed consent.

Provenance and peer review Not commissioned; externally peer reviewed.

Data availability statement Data are available upon reasonable request. All data relevant to the study can be attained through reasonable request from the principal investigator (ruth.piers@ ugent.be).

Open access This is an open access article distributed in accordance with the Creative Commons Attribution Non Commercial (CC BY-NC 4.0) license, which permits others to distribute, remix, adapt, build upon this work noncommercially, and license their derivative works on different terms, provided the original work is properly cited, appropriate credit is given, any changes made indicated, and the use is noncommercial. See: http://creativecommons.org/licenses/by-nc/4. $0 /$.

\section{ORCID iD}

Ruth Piers http://orcid.org/0000-0001-5261-220X

\section{REFERENCES}

1 Finnbakk E, Skovdahl K, Blix ES, et al. Top-level managers and politicians' worries about future care for older people with complex and acute illnesses: a Nordic study. Int J Older People Nurs 2012;7:163-72.

2 Clegg A, Young J, Iliffe S, et al. Frailty in elderly people. Lancet 2013;381:752-62.

3 Goldsbury DE, O'Connell DL, Girgis A, et al. Acute hospital-based services used by adults during the last year of life in New South Wales, Australia: a populationbased retrospective cohort study. BMC Health Serv Res 2015;15:537.

4 Rosenwax LK, McNamara BA, Murray K, et al. Hospital and emergency department use in the last year of life: a baseline for future modifications to end-of-life care. Med J Aust 2011;194:570-3.

5 Detering KM, Hancock AD, Reade MC, et al. The impact of advance care planning on end of life care in elderly patients: randomised controlled trial. BMJ 2010;340:c1345.

6 Gaertner J, Siemens W, Meerpohl JJ, et al. Effect of specialist palliative care services on quality of life in adults with advanced incurable illness in hospital, hospice, or community settings: systematic review and meta-analysis. $B M J$ 2017;357:j2925.

7 Kavalieratos D, Corbelli J, Zhang D, et al. Association between palliative care and patient and caregiver outcomes: a systematic review and meta-analysis. JAMA 2016;316:2104-14.

8 Kelley AS, Morrison RS. Palliative care for the seriously ill. $N$ Engl J Med 2015;373:747-55.

9 Brereton L, Clark J, Ingleton C, et al. What do we know about different models of providing palliative care? Findings from a systematic review of reviews. Palliat Med 2017;31:781-97.

10 Gardiner C, Cobb M, Gott M, et al. Barriers to providing palliative care for older people in acute hospitals. Age Ageing 2011;40:233-8.

11 Harwood RH, Enguell H. End-Of-Life care for frail older people. BMJ Support Palliat Care 2019. doi:10.1136/ bmjspcare-2019-001953. [Epub ahead of print: 15 Nov 2019].

12 Nicholson C, Morrow EM, Hicks A, et al. Supportive care for older people with frailty in hospital: an integrative review. Int J Nurs Stud 2017;66:60-71.

13 Chow J, Senderovich H. It's time to talk: challenges in providing integrated palliative care in advanced congestive heart failure. A narrative review. Curr Cardiol Rev 2018;14:128-37.

14 Highet G, Crawford D, Murray SA, et al. Development and evaluation of the supportive and palliative care indicators tool (SPICT): a mixed-methods study. BMJ Support Palliat Care 2014;4:285-90.

15 Gill TM. The central role of prognosis in clinical decision making. JAMA 2012;307:199-200.

16 Malhotra K, Fenton JJ, Duberstein PR, et al. Prognostic accuracy of patients, caregivers, and oncologists in advanced cancer. Cancer 2019;125:2684-92.

17 De Bock R, Van Den Noortgate N, Piers R. Validation of the supportive and palliative care indicators tool in a geriatric population. J Palliat Med 2018;21:220-4.

18 Mudge AM, Douglas C, Sansome X, et al. Risk of 12-month mortality among hospital inpatients using the surprise question and SPICT criteria: a prospective study. BMJ Support Palliat Care 2018;8:213-20.

19 Katz S, Ford AB, Moskowitz RW, et al. Studies of illness in the aged. The index of ADL: a standardized measure of biological and psychosocial function. JAMA 1963;185:914-9.

20 Lawton MP, Brody EM. Assessment of older people: selfmaintaining and instrumental activities of daily living. Gerontologist 1969;9:179-86.

21 Charlson M, Szatrowski TP, Peterson J, et al. Validation of a combined comorbidity index. J Clin Epidemiol 1994;47:1245-51.

22 Reitsma JB, Glas AS, Rutjes AWS, et al. Bivariate analysis of sensitivity and specificity produces informative summary measures in diagnostic reviews. J Clin Epidemiol 2005;58:982-90.

23 Mallett S, Halligan S, Thompson M, et al. Interpreting diagnostic accuracy studies for patient care. BMJ 2012;345:e3999.

24 Gómez-Batiste X, Martínez-Muñoz M, Blay C, et al. Utility of the NECPAL CCOMS-ICO ${ }^{\odot}$ tool and the Surprise Question as screening tools for early palliative care and to predict mortality in patients with advanced chronic conditions: A cohort study. Palliat Med 2017;31:754-63.

25 Gómez-Aguirre N, Fuertes-Ruiz D, Gracia-Tello B, et al. External validation of the PALIAR index for patients with advanced, nononcologic chronic diseases. Aging Clin Exp Res 2019;31:393-402.

26 Rockwood K, Song X, MacKnight C, et al. A global clinical measure of fitness and frailty in elderly people. CMAJ 2005;173:489-95.

27 Ritt M, Bollheimer LC, Sieber CC, et al. Prediction of one-year mortality by five different frailty instruments: a comparative 
study in hospitalized geriatric patients. Arch Gerontol Geriatr 2016;66:66-72.

28 White N, Kupeli N, Vickerstaff V, et al. How accurate is the 'Surprise Question' at identifying patients at the end of life? A systematic review and meta-analysis. BMC Med 2017;15:139.

29 Downar J, Goldman R, Pinto R, et al. The "surprise question" for predicting death in seriously ill patients: a systematic review and meta-analysis. CMAJ 2017;189:E484-93.

30 Pilotto A, Veronese N, Daragjati J, et al. Using the multidimensional prognostic index to predict clinical outcomes of hospitalized older persons: a prospective, multicenter, International study. J Gerontol A Biol Sci Med Sci 2019;74:1643-9.

31 Levy WC, Mozaffarian D, Linker DT, et al. The Seattle heart failure model: prediction of survival in heart failure. Circulation 2006;113:1424-33.

32 Fu S, Xie L, Li D, et al. The predictive capacity and additional prognostic power of $\mathrm{N}$-terminal pro-B-type natriuretic peptide in Chinese elderly with chronic heart failure. Clin Interv Aging 2015; $10: 359$.

33 Sprung CL, Maia P, Bulow H-H, et al. The importance of religious affiliation and culture on end-of-life decisions in European intensive care units. Intensive Care Med 2007;33:1732-9.

34 Perry LM, Hoerger M, Malhotra S, et al. Development and validation of the palliative care attitudes scale (PCAS-9): a measure of patient attitudes toward palliative care. J Pain Symptom Manage 2020;59:293-301.

35 Boyd K, Moine S, Murray SA, et al. Should palliative care be rebranded? BMJ 2019;364:1881.

36 Warnier RMJ, van Rossum E, van Velthuijsen E, et al. Validity, reliability and feasibility of tools to identify frail older patients in inpatient hospital care: a systematic review. J Nutr Health Aging 2016;20:218-30.

37 Walsh RI, Mitchell G, Francis L, et al. What diagnostic tools exist for the early identification of palliative care patients in general practice? A systematic review. J Palliat Care 2015;31:118-23.

38 Albers G, Froggatt K, Van den Block L, et al. A qualitative exploration of the Collaborative working between palliative care and geriatric medicine: barriers and facilitators from a European perspective. BMC Palliat Care 2016;15:47.

39 Quill TE, Abernethy AP. Generalist plus specialist palliative care--creating a more sustainable model. N Engl J Med 2013;368:1173-5.

40 Siouta N, Van Beek K, van der Eerden ME, et al. Integrated palliative care in Europe: a qualitative systematic literature review of empirically-tested models in cancer and chronic disease. BMC Palliat Care 2016;15:56.

41 Singer AE, Goebel JR, Kim YS, et al. Populations and interventions for palliative and end-of-life care: a systematic review. J Palliat Med 2016;19:995-1008. 